\title{
Minimizing the Level of Bacillus cereus Spores in Farm Tank Milk
}

\author{
M. M. M. Vissers, ${ }^{* 1}$ M. C. Te Giffel, ${ }^{\star}$ F. Driehuis, ${ }^{\star}$ P. De Jong, $†$ and J. M. G. Lankveld‡ \\ *Department of Health and Safety, and \\ †Department of Processing, NIZO Food Research, PO Box 20, 6710 BA Ede, the Netherlands \\ ¥Chair of Dairy Science, Wageningen University and Research Centre, PO Box 8129, 6700 EV Wageningen, the Netherlands
}

\begin{abstract}
In a year-long survey on 24 Dutch farms, Bacillus cereus spore concentrations were measured in farm tank milk (FTM), feces, bedding material, mixed grass and corn silage, and soil from the pasture. The aim of this study was to determine, in practice, factors affecting the concentration of $B$. cereus spores in FTM throughout the year. In addition, the results of the survey were used in combination with a previously published modeling study to determine requirements for a strategy to control $B$. cereus spore concentrations in FTM below the MSL of $3 \log _{10}$ spores/L. The B. cereus spore concentration in FTM was $1.2 \pm 0.05 \log _{10}$ spores/ $\mathrm{L}$ and in none of samples was the concentration above the MSL. The spore concentration in soil $(4.9 \pm 0.04$ $\log _{10}$ spores/g) was more than 100 -fold higher than the concentration in feces $\left(2.2 \pm 0.05 \log _{10}\right.$ spores/g), bedding material $\left(2.8 \pm 0.07 \log _{10}\right.$ spores/g), and mixed silage $\left(2.4 \pm 0.07 \log _{10}\right.$ spores/g). The spore concentration in FTM increased between July and September compared with the rest of the year $\left(0.5 \pm 0.02 \log _{10}\right.$ spores/L difference). In this period, comparable increases of the concentrations in feces $\left(0.4 \pm 0.03 \log _{10}\right.$ spores/g), bedding material ( $0.5 \pm 0.05 \log _{10}$ spores/g), and mixed silage $\left(0.4 \pm 0.05 \log _{10}\right.$ spores/g) were found. The increased $B$. cereus spore concentration in FTM was not related to the grazing of cows. Significant correlations were found between the spore concentrations in FTM and feces $(\mathrm{r}=$ $0.51)$ and in feces and mixed silage $(r=0.43)$ when the cows grazed. The increased concentrations during summer could be explained by an increased growth of $B$. cereus due to the higher temperatures. We concluded that year-round $B$. cereus spores were predominantly transmitted from feeds, via feces, to FTM. Farmers should take measures that minimize the transmission of spores via this route by ensuring low initial contamination levels in the feeds $\left(<3 \log _{10}\right.$ spores/g) and by
\end{abstract}

Received December 21, 2006.

Accepted March 23, 2007.

${ }^{1}$ Corresponding author: marc.vissers@nizo.nl preventing growth of $B$. cereus in the farm environment. In addition, because of the extremely high $B$. cereus spore concentrations in soil, the contamination of teats with soil needs to be prevented.

Key words: Bacillus cereus, raw milk, farm management, microbiology

\section{INTRODUCTION}

Growth of the spore-forming Bacillus cereus often limits the shelf life of pasteurized dairy products kept at refrigerator temperatures. The bacterium grows facultatively anaerobically over a wide range of temperatures $\left(4\right.$ to $\left.55^{\circ} \mathrm{C}\right), \mathrm{pH}(4.9$ to 9.3 ), and water activities (0.92 to 1.0; Scientific Panel on Biological Hazards, 2004). Dairy products spoiled by B. cereus show defects such as off-flavors, sweet curdling, and bitty cream (Stone and Rowlands, 1952; Overcast and Atmaram, 1971). Bacillus cereus in dairy products originates from the farm environment or from recontamination during processing (Te Giffel et al., 1996; Lin et al., 1998; Svensson et al., 2000).

A chain-management approach is important to prevent spoilage of pasteurized dairy products by $B$. cereus. Major control options comprise minimizing the $B$. cereus spore concentration in farm tank milk (FTM), removing spores from raw milk via bactofugation or microfiltration, and preventing recontamination and growth during processing and storage. With respect to the shelf life of pasteurized dairy products, a maximum spore limit (MSL) for B. cereus of $3 \log _{10}$ spores/L in FTM is necessary to achieve a shelf life for pasteurized milk of at least $7 \mathrm{~d}$ (Walstra et al., 2005). The highest concentrations are generally observed during summer and early autumn (Phillips and Griffiths, 1986; Sutherland and Murdoch, 1994; Te Giffel et al., 1995).

Farm tank milk can be contaminated with $B$. cereus spores that originate from feeds and soil via the exterior of teats or via the surface of the milking equipment (Griffiths and Phillips, 1990; Saran, 1995; Slaghuis et al., 1997). After the initial contamination caused by microbial growth, the concentration can increase further during (incorrect) storage of the milk on the farm. The soil-milk route is dominant during the grazing of 
cows, whereas the feed-milk route is dominant during the housing of cows (Slaghuis et al., 1997; Christiansson et al., 1999).

Simulation models have indicated that control of the $B$. cereus spore concentration in feeds, below $3 \log _{10}$ spores $/ g$, and prevention of growth of $B$. cereus in the mixed silage offered to cows in the barn are the most important measures to ensure FTM concentrations below the MSL when cows are housed (Vissers et al., 2007b). When cows graze and teats are contaminated with soil, the transmission of soil to FTM should be minimized to meet this criterion. Based on model simulations, no increase in $B$. cereus spore concentration during storage of FTM is expected when the farm tank meets regulation 5708 of the International Organization for Standardization (ISO, 1983).

The aim of this study was to determine in practice, via a year-long survey on 24 Dutch farms, factors that affect the concentration of B. cereus spores in FTM. In addition, the results of the survey were used in combination with a previously published modeling study to determine requirements for a strategy to control the $B$. cereus spore concentration in FTM below the MSL.

\section{MATERIALS AND METHODS}

\section{Sample Collection}

Samples were collected on 24 farms across the Netherlands. The farms were selected for a study on the control of FTM with spores of butyric acid bacteria (BAB) that was conducted simultaneously with the study described in this paper (Vissers et al., 2007a). Selection of farms was based on the contamination of FTM with BAB spores in 2004. Farms were classified into 3 groups: 1) a group of 10 farms that received no deduction on the milk price because of a high level of contamination of FTM with spores of BAB in 2004; 2) a group of 9 farms that occasionally received a deduction ( $<20 \%$ of the FTM deliveries); and 3 ) a group of 5 farms that regularly received a deduction $(>20 \%$ of the FTM deliveries). The selection based on BAB spores in FTM did not introduce a bias with regard to $B$. cereus spores because data analyses showed no relationship between BAB spore concentrations in FTM in 2004 and 2005 (Vissers et al., 2007a) and no relationship between the concentrations of $B$. cereus and BAB spores in FTM and environmental carriers such as soil, feed, and feces (this study).

The farms were visited 6 times between January and December 2005 at regular intervals of 8 wk. During each visit, samples were collected by trained personal and a questionnaire was filled out to collect farm management data. Each farm was visited by the same person. The questionnaire contained questions related to the ration fed, cows, housing conditions, and milking practices. The aspects of farm management evaluated were barn type (loose vs. tied housing of cows), feeds fed, bedding material used (straw or sawdust), boxcleaning frequency (once daily vs. less than once daily), the presence of cows preferring to lie down on dirty patches, forestripping, teat-cleaning method (dry vs. moist towel), and frequency of an acid rinse of the milking equipment (once weekly or more vs. less than once weekly). Whether the pasture was wet or dry was recorded when cows were grazing.

The following sample types were collected: FTM (every visit), feces from the barn (when cows were housed half or all day), feces from the pasture (when cows were grazing all day), bedding material from the barn (when cows were housed half or all day), soil (when cows were at pasture half or all day), and mixed grass and corn silage fed to the cows in the barn (every visit when appropriate). Soil samples were collected from the pasture and surface of walking paths. All samples except the FTM sample were composite samples consisting of 10 randomly mixed collected subsamples. Samples were stored at 4 to $6^{\circ} \mathrm{C}$ until microbial analysis within $24 \mathrm{~h}$ after sample collection.

\section{Microbial Analyses}

Feces, bedding, soil, and silage and feed extracts were prepared by adding $90 \mathrm{~mL}$ of peptone physiological salt solution ( $1 \mathrm{~g}$ of neutralized bacteriological peptone and $8.5 \mathrm{~g}$ of sodium chloride/L) to $10 \mathrm{~g}$ of sample and homogenizing for $2 \mathrm{~min}$ in a laboratory blender (Stomacher, Seward Medical, London, UK). The concentration of $B$. cereus spores was determined according to Dutch standard 6875 (NEN-ISO, 1994). Farm tank milk samples $(100 \mathrm{~mL})$ and extract $(10 \mathrm{~mL})$ were heated at $80^{\circ} \mathrm{C}$ for 5 min. After cooling, pasteurized FTM samples were centrifuged for $30 \mathrm{~min}$ at $3,000 \times \mathrm{g}$. Serial dilutions of pellet and cooled pasteurized extracts in peptone physiological salt solution were prepared. Bacillus cereus spores were enumerated by surface plating on mannitol egg yolk polymyxin agar. Mannitol egg yolk polymyxin plates were aerobically incubated at $30^{\circ} \mathrm{C}$ for $24 \mathrm{~h}$. Typical pink colonies surrounded by a zone of precipitation were counted. Pink colonies were isolated and confirmed as B. cereus by testing for anaerobic acid production from glucose. In addition, 16S- and cold shock protein A-PCR typing measurements were performed to confirm the identity of the colonies.

\section{Statistical Analyses}

Statistical calculations were performed using Statistica (StatSoft Inc., Tulsa, OK) and Microsoft Excel (Mi- 


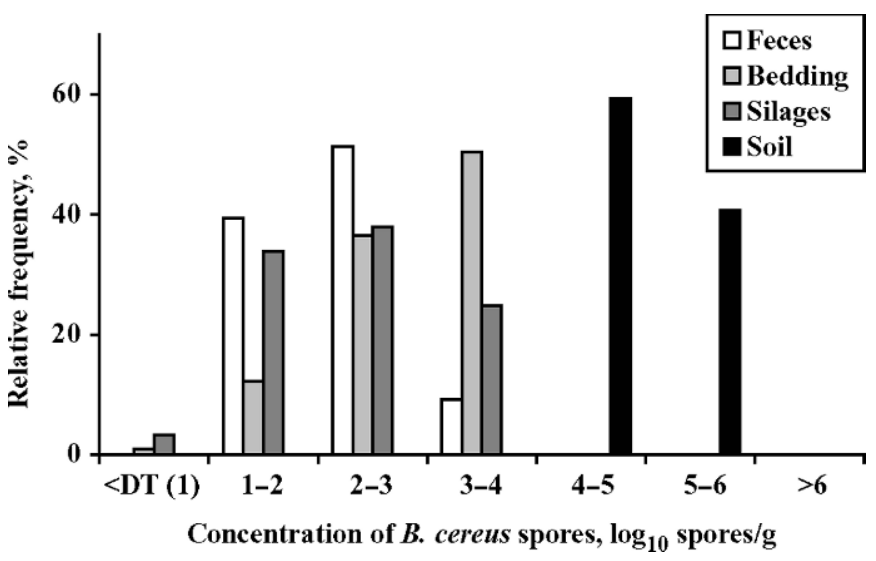

Figure 1. Distribution of concentrations of Bacillus cereus spores measured in feces, bedding material, mixed silage, and soil. DT = detection limit.

crosoft, Redmond, WA). To perform statistical analyses, samples with a $B$. cereus spore concentration below the detection limit were assigned a concentration equaling half the detection limit. All statistical analyses were performed on $\log _{10}$-transformed data. Student's $t$-tests were used to detect significant differences among farms, environmental carriers, and aspects of farm management. Fisher's exact tests were used to determine whether a low or high concentration occurred more frequently in a specific carrier or group. In addition, Pearson and rank order correlation analyses were performed.

\section{RESULTS}

\section{Concentration in Environmental Carriers}

Figure 1 summarizes the $B$. cereus spore concentrations found in different environmental carriers. In total, 142 feces samples, 114 samples of bedding materials, 117 mixed corn and grass silage samples, and 59 soil samples were analyzed. Overall, soil contained the most spores $(P<0.01)$. In bedding material $2.8 \pm 0.07 \log _{10}$ spores/g was found. Concentrations in feces $(2.2 \pm 0.05$ $\log _{10}$ spores/g) and in mixed silage $\left(2.4 \pm 0.07 \log _{10}\right.$ spores/g) were significantly lower than those in bedding material $(P<0.01)$. No accumulation of spores in feces was found; the average concentrations in feces and mixed silage did not differ significantly $(2.2 \pm 0.05$ vs. $2.4 \pm 0.07 ; P=0.10$ ).

The concentration in soil $\left(4.9 \pm 0.04 \log _{10}\right.$ spores $\left./ g\right)$ was about 100 times higher than the concentrations in other environmental carriers. The concentration in soil showed less variation (i.e., a factor of $100 \mathrm{vs}$. a factor of more than 1,000) between the minimum and maximum level (Figure 1). Concentrations were independent of the type of soil (sand, clay, or peat).

\section{Concentrations in FTM}

Figure 2 shows the distribution of $B$. cereus spore concentrations in FTM measured on the 24 farms during the survey and the predicted concentrations using model simulations, assuming that all B. cereus spores in FTM originated from feeds (Vissers et al., 2007b). There was good agreement between measured and predicted concentrations. In the survey, none of the 140 FTM samples exceeded the MSL. The median concentration, $1.0 \log _{10}$ spores/L, was a factor of 100 below the MSL. The average concentration was $1.2 \pm 0.05 \log _{10}$ spores/L.

In our survey, cows were grazing at least half the day on 52 of the total 144 visits. On 8 of these 52 visits, the pasture was wet because of rainfall. Even so, no differences were found between dry and wet weather conditions. The median and average $B$. cereus spore concentrations measured in FTM of cows grazing at least half the day were $1.3 \pm 0.07$ and $1.4 \pm 0.08 \log _{10}$ spores/L, respectively.

\section{Seasonal Trends}

During the summer months (July to September) the B. cereus spore concentration in FTM was significantly higher than in the rest of the year (difference of 0.5 $\log _{10}$ spores/L; $P<0.01$ ). In this period, the spore concentrations in feces, bedding material, and mixed silage were increased by 0.4 to $0.5 \log _{10}$ spores/g $(P<0.01)$. In soil, this change in the $B$. cereus spore concentration was not observed.

We postulated that the increased $B$. cereus spore concentration in FTM during the summer period was associated with contamination of teats with soil during grazing (Slaghuis et al., 1997; Christiansson et al., 1999). This hypothesis was tested using the data from the survey. Data collected during the period in which farms were applying pasturing (grazing period: May to October) were divided into 3 groups according to the housing situation of the cows in that period: 1) cows housed all day ( $27 \%$ of the visits during the pasturing period), 2) cows housed during the night and grazing during the daytime (54\% of the visits during the pasturing period), and 3 ) cows grazing all day (20\% of the visits during the pasturing period). On 5 farms, cows were housed all day during the entire grazing period. On only 1 farm were cows grazing all day during the entire grazing period. On the other 18 farms, housing and grazing of cows was changed on a regular basis. In addition, a fourth data set was distinguished, consisting of the $B$. 


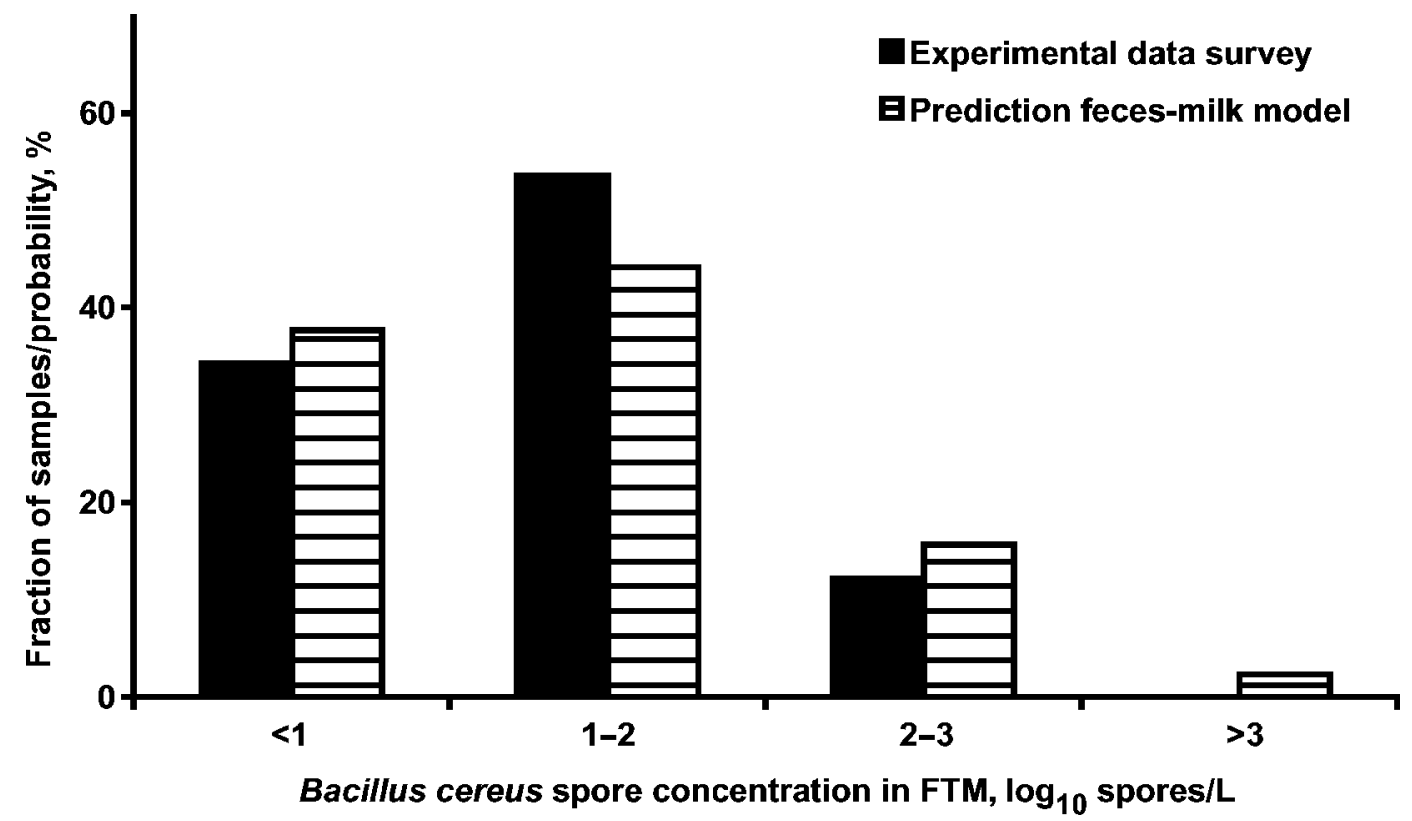

Figure 2. Distribution of farm tank milk (FTM) concentration measured in the survey and predicted with a simulation model (Vissers et al., 2007b).

cereus spore concentrations collected in the period when cows were housed all day on all farms (housing period: November to April). Table 1 gives an overview of the $B$. cereus spore concentrations measured in FTM for the 4 groups. Table 2 summarizes the concentrations measured in the environmental carriers for the 4 groups.

No effect of grazing was observed. No significant differences were detected in $B$. cereus spore concentrations in FTM among the 3 housing situations occurring during the grazing period (Table 1). A lower spore concentration was detected during the housing period compared with pasture during the daytime in the grazing period. Even so, this is likely related to the observed seasonal trend in the spore concentration as described at the beginning of this section. Similar results were obtained for the B. cereus spore concentrations in feces, bedding material, and mixed silage (Table 2): concentrations detected during the grazing period were not affected by the housing situation, whereas during the housing period a lower concentration was detected.

The observed seasonal trend and data summarized in Tables 1 and 2 suggest that the $B$. cereus spore concentration in FTM was related to the spore concentrations in feces and mixed silage. Table 3 shows the Pearson correlation coefficients between different carriers for the situation in which cows were most likely not in contact with soil (housed all day in the barn) and the situation in which cows were in contact with soil (grazing during the daytime or grazing $24 \mathrm{~h} / \mathrm{d}$ ). Spearman

Table 1. Bacillus cereus spore concentrations in farm tank milk in different situations (housing period: November to April; grazing period: May to October)

\begin{tabular}{|c|c|c|c|c|c|}
\hline \multirow[b]{2}{*}{ Housing situation } & \multirow[b]{2}{*}{$\begin{array}{c}\text { Mean }(\mathrm{SE}),{ }^{1} \\
\log _{10} \\
\text { spores/L }\end{array}$} & \multirow[b]{2}{*}{$\begin{array}{l}\text { Median, } \\
\log _{10} \\
\text { spores/L }\end{array}$} & \multirow[b]{2}{*}{$\begin{array}{c}\text { Range, } \\
\log _{10} \\
\text { spores/L }\end{array}$} & \multicolumn{2}{|c|}{$\begin{array}{l}\text { Fraction of samples } \\
\text { with a concentration }\end{array}$} \\
\hline & & & & $\begin{array}{c}\text { Below } \\
1 \log _{10} \\
\text { spores/L, } 2 \%\end{array}$ & $\begin{array}{c}\text { Above } \\
2 \log _{10} \\
\text { spores/L, }{ }^{2} \%\end{array}$ \\
\hline Barn all day (housing period; $n=66$ ) & $1.0(0.05)^{\mathrm{a}}$ & 1.0 & $<1.0-2.2$ & $47^{\mathrm{b}}$ & $3^{\mathrm{a}}$ \\
\hline Barn 24 h/d (grazing period; $\mathrm{n}=19$ ) & $1.3(0.16)^{\mathrm{ab}}$ & 1.3 & $<1.0-2.4$ & $37^{\mathrm{ab}}$ & $21^{\mathrm{b}}$ \\
\hline
\end{tabular}

${ }^{\mathrm{a}, \mathrm{b}}$ Different superscripts indicate differences $(P<0.05)$.

${ }^{1}$ Student's $t$-test was used to detect significant differences.

${ }^{2}$ Fisher's exact test was used to detect significant differences. 
Table 2. Effects of Bacillus cereus spore concentration in environmental carriers in different situations (housing period: November to April; grazing period: May to October)

\begin{tabular}{|c|c|c|c|c|c|c|c|c|}
\hline \multirow[b]{2}{*}{ Housing situation } & \multicolumn{2}{|c|}{$\begin{array}{c}\text { Feces, } \\
\log _{10} \text { spores/g }\end{array}$} & \multicolumn{2}{|c|}{$\begin{array}{l}\text { Bedding material, } \\
\log _{10} \text { spores/g }\end{array}$} & \multicolumn{2}{|c|}{$\begin{array}{l}\text { Mixed silage } \\
\log _{10} \text { spores/g }\end{array}$} & \multicolumn{2}{|c|}{$\begin{array}{c}\text { Soil, } \\
\log _{10} \text { spores/g }\end{array}$} \\
\hline & Mean $(\mathrm{SE})^{1}$ & Range & Mean $(\mathrm{SE})^{1}$ & Range & Mean $(\mathrm{SE})^{1}$ & Range & Mean $(\mathrm{SE})^{1}$ & Range \\
\hline Barn 24 h/d (grazing period; $\mathrm{n}=19$ ) & $2.2(0.16)^{\mathrm{ab}}$ & $1.2-3.5$ & $2.9(0.18)^{\mathrm{ab}}$ & $<1.0-3.7$ & $2.8(0.16)^{\mathrm{b}}$ & $1.5-3.7$ & & \\
\hline $\begin{array}{l}\text { At pasture during daytime (grazing } \\
\text { period; } \mathrm{n}=38 \text { ) }\end{array}$ & $2.5(0.09)^{\mathrm{b}}$ & $1.4-3.7$ & $3.1(0.08)^{b}$ & $2.1-4.0$ & $2.6(0.16)^{b}$ & $<1.0-4.0$ & $4.9(0.05)^{\mathrm{a}}$ & $4.1-6.0$ \\
\hline
\end{tabular}

${ }^{\mathrm{a}, \mathrm{b}}$ Different superscripts within a column indicate differences $(P<0.05)$.

${ }^{1}$ Student's $t$-test was used to detect significant differences.

rank order correlation coefficients were similar. In both situations, significant correlations $(P<0.001)$ were found between the spore concentrations in mixed silage and feces and in feces and FTM. In contrast, no correlation was established between the spore concentrations in soil and FTM.

\section{Effects of Farm Management}

Significant differences were observed in the B. cereus spore concentrations in FTM among farms. Again, this appeared to be related to the $B$. cereus spore concentrations in feces, bedding material, and mixed silage. The FTM concentration on the 6 farms with the lowest $B$. cereus spore concentrations was $0.5 \pm 0.07 \log _{10}$ spores/ $\mathrm{L}(P<0.01)$ lower than that on the 6 farms with the highest concentrations. Housing conditions during the grazing period were similar for the farms with the highest and lowest average spore concentrations. On the 6 farms with the lowest average concentration in FTM, the concentrations in feces $\left(0.3 \pm 0.10 \log _{10}\right.$ spores/g difference; $P=0.03)$, bedding material $\left(0.4 \pm 0.12 \log _{10}\right.$

Table 3. Pearson correlation coefficients between different carriers ${ }^{1}$

\begin{tabular}{|c|c|c|c|}
\hline Item & All data & $\begin{array}{c}\text { Cows } \\
\text { in barn } \\
24 \mathrm{~h} / \mathrm{d}\end{array}$ & $\begin{array}{c}\text { Cows } \\
\text { grazing } \\
\text { during the } \\
\text { daytime } \\
\text { or } 24 \mathrm{~h} / \mathrm{d}\end{array}$ \\
\hline Milk vs. feces & $0.51 * * *$ & $0.45^{* * *}$ & $0.44^{* * *}$ \\
\hline Milk vs. bedding material & $0.26^{* *}$ & NS & NS \\
\hline Milk vs. mixed silage & $0.20 *$ & NS & NS \\
\hline Milk vs. soil & NS & NS & NS \\
\hline Feces vs. bedding material & $0.37 * * *$ & $0.33^{* *}$ & NS \\
\hline Feces vs. mixed silage & $0.43 * * *$ & $0.38^{* * * *}$ & $0.50^{* * *}$ \\
\hline Bedding material vs. mixed silage & $0.29 * *$ & NS & $0.45^{* *}$ \\
\hline
\end{tabular}

${ }^{1}$ Spearman rank order correlation coefficients were similar.

$* P<0.05 ; * * P<0.01 ; * * * P<0.001$. spores/g difference; $P=0.03)$, and mixed silage $(0.3 \pm$ $0.12 \log _{10}$ spores/g difference; $P=0.04$ ) were significantly lower. The average concentrations in the environmental carriers on the other 12 farms were between the mean concentrations measured on the 6 farms with the lowest and the 6 farms with the highest average $B$. cereus spore concentrations in FTM. Overall, it can be concluded that the variance between farms was large.

On each visit, different aspects of farm management were inventoried with a questionnaire. The following aspects of farm management were evaluated: barn type (loose vs. tied housing of cows), bedding material used (straw or sawdust), box-cleaning frequency (once daily vs. less than once daily), the presence of cows preferring to lie down on dirty patches, forestripping, teat-cleaning method (dry vs. moist towel; all farms used multiple-use towels), and frequency of an acid rinse of the milking equipment (once weekly or more vs. less than once weekly). Nonetheless, none of the inventoried aspects resulted in a significant effect on the $B$. cereus spore concentration in FTM.

\section{B. cereus and BAB Spore Concentration in FTM}

The field survey was used to study the contamination of FTM with BAB spores (Vissers et al., 2007a). Analysis of both data sets showed no correlation between $B$. cereus and $\mathrm{BAB}$ spore concentrations in FTM (Pearson rank order correlation coefficient of $0.10 ; P>0.2)$. In addition, the farms that produced FTM with the lowest average concentration of $B$. cereus spores were not the same farms that produced FTM with the lowest average $\mathrm{BAB}$ spore concentration. In contrast to FTM, B. cereus and $\mathrm{BAB}$ spore concentrations in mixed silages and feces were significantly correlated, although the correlation coefficients were low $(\mathrm{r}=0.35, P=0.004$; and $\mathrm{r}=$ $0.20, P=0.02$, respectively). 


\section{DISCUSSION}

\section{Dominant Contamination Pathway}

The B. cereus spore concentrations measured in FTM, feces, bedding material, and mixed silage on the 24 farms were comparable with previous reports (Te Giffel et al., 1995; Slaghuis et al., 1997; Christiansson et al., 1999). The range of spore concentrations in soil detected in this study (4 to $6 \log _{10}$ spores/g; Figure 1) was less than in the studies by Te Giffel et al. (1995) and Slaghuis et al. (1997). In the latter studies, concentrations between 1 and $6 \log _{10}$ spores/g were detected when using the same method for enumeration. The cause for this discrepancy is unknown.

In contrast to Slaghuis et al. (1997) and Christiansson et al. (1999), we observed no effect of grazing on the $B$. cereus spores concentration in FTM (Tables 1 and 2). In addition, we observed no effect of wet weather conditions, although this may be due to the limited number of samples collected under wet weather conditions. Our data indicate that year-round, the B. cereus spore concentration measured in FTM depended mostly on the spore concentration in mixed silage offered to the cows and the transmission of feces to FTM (Table 3). First, similar seasonal patterns were observed for FTM, feces, and mixed silage (Tables 1 and 2). Second, farms with the lowest average spore concentration in FTM also fed silages with the lowest spore concentration. And third, significant correlations between FTM and feces and between feces and mixed silage were found even when cows were grazing during the daytime or $24 \mathrm{~h} / \mathrm{d}$ (Table 3). The correlation coefficients were relatively low. On the other hand, no correlations or trends were observed between spore concentrations in FTM and soil, even when cows grazed all day. In addition, the correspondence between the $B$. cereus spore concentrations measured in FTM in the survey and the B. cereus spore concentrations predicted by a simulation model underline the point that in the survey, spores in FTM primarily originated from feed (Figure 2). For the model predictions, we assumed that all B. cereus spores in FTM originated from feed and were transmitted to FTM via feces. If a significant amount of spores had been transmitted from the soil to FTM, deviations between the measured and predicted distribution of $B$. cereus spore concentrations in FTM would have been found (Vissers et al., 2007a).

Assuming that the transmission of $B$. cereus from feed, via feces, to FTM is the dominant route all year round, the increased spore concentrations detected during the summer months suggests that at some stage(s) of the contamination pathway, growth of B. cereus occurred, for instance, in mixed silage and bedding material. During the summer, the temperature is higher,
Table 4. Amount of feces or soil that needs to be transmitted to farm tank milk (FTM) to give an FTM Bacillus cereus spore concentration of 1 and $3 \log _{10}$ spores/L

\begin{tabular}{|c|c|c|c|}
\hline \multirow[b]{2}{*}{ Concentration } & \multirow[b]{2}{*}{$\begin{array}{l}\text { Concentration, } \\
\log _{10} \mathrm{cfu} / \mathrm{g}\end{array}$} & \multicolumn{2}{|c|}{$\begin{array}{c}\text { FTM concentration, } \\
\text { mg/L }\end{array}$} \\
\hline & & $\begin{array}{l}1 \log _{10} \\
\text { spores/L }\end{array}$ & $\begin{array}{c}3 \log _{10} \\
\text { spores/L } \\
(\mathrm{MSL})^{1}\end{array}$ \\
\hline \multicolumn{4}{|l|}{ In feces } \\
\hline Observed median & 2.1 & 71 & 7,100 \\
\hline Observed maximum & 3.8 & 2 & 170 \\
\hline \multicolumn{4}{|l|}{ In soil } \\
\hline Observed median & 4.9 & 0.1 & 13 \\
\hline Observed maximum & 6.0 & 0.01 & 1 \\
\hline
\end{tabular}

${ }^{1} \mathrm{MSL}=$ maximum acceptable spore level.

and as a result, microbial growth rates are most likely higher than during the winter (Benedict et al., 1993). Consequently, $B$. cereus spore concentrations in the silage or bedding material may increase, resulting in higher spore concentrations in FTM.

The results of this study did not confirm the results of the study by Christiansson et al. (1999), who concluded that elevated concentrations of $B$. cereus spores in FTM were associated with higher levels of soil contamination of teats during grazing. In the current study, transmission of spores via feed and feces was clearly the dominant pathway, although it is possible that a minority of the spores in FTM originated from soil. Moreover, there may be circumstances in which transmission of spores via soil contamination of teats will be the dominant pathway, for instance, when cows are grazing in periods with a considerable amount of rainfall. Another potential factor of influence may the amount of soil that cows ingest during grazing, which generally is greatest when the grass is short, for instance, because of slow grass growth (Dewes, 1996).

Although this study shows that transmission of $B$. cereus spores to FTM via feces is the dominant pathway, it does not imply that the transmission of $B$. cereus spores via soil is irrelevant. Table 4 shows the amounts of feces and soil, based on the observed median and maximum concentrations in our survey, that have to be transmitted to $1 \mathrm{~L}$ of FTM to obtain a concentration in FTM of $1 \log _{10}$ spores/L (observed median concentration) and $3 \log _{10}$ spores/L (MSL). As Table 3 demonstrates, the transmission of small amounts of soil, 1 to $13 \mathrm{mg} / \mathrm{L}$, can be problematic for the microbial quality of FTM. We concluded that at least $2 \mathrm{mg} / \mathrm{L}$ (average of approximately $40 \mathrm{mg} / \mathrm{L}$ ) is transmitted to milk via the exterior of teats during confinement of cows (Stadhouders and Jørgensen, 1990). Nevertheless, the survey results indicate that generally $<1 \mathrm{mg}$ of soil/L of FTM is transmitted. If $>1 \mathrm{mg}$ of soil had been regularly trans- 
mitted to $1 \mathrm{~L}$ of FTM, the concentration above the MSL would have been measured occasionally. These data indicate that where the risk of contamination of teats with soil is high, care should be taken to keep the teats clean. Moist weather and dirty walking paths were associated with the contamination of teats with soil and increased the concentration in FTM (Christiansson et al., 1999), yet the B. cereus spore concentration in milk did not exceed the MSL. From the results of this survey we concluded that year round, during housing and grazing, B. cereus spores from feeds, via feces, were transmitted to FTM, but that concentrations in FTM above the MSL were more likely due to the transmission of spores from soil to FTM. This implies that although the feed-feces-FTM pathway is generally dominant, control of the soil-FTM pathway is most important for the dairy industry.

\section{Control Strategy}

A major objective of the study was to develop a strategy to ensure a $B$. cereus spore concentration in FTM below the MSL. To meet this objective, it is important to control the dominant contamination pathway (feedfeces-FTM). Previous model simulations showed that this can be achieved by maintaining an initial contamination level of all feeds, including silages, below $3 \log _{10}$ spores/g and by preventing growth in the mixed silage (Vissers et al., 2007b). Options to prevent or limit the possibility of growth are a $\mathrm{pH}$ of below 5 in the mixed silage (and bedding material) and a relatively high frequency of refreshing the mixed silage offered to cows in the barn and the bedding material (at least once daily). These requirements are generally met, and consequently, the $B$. cereus spore concentration in FTM is usually below the MSL. Yet under certain circumstances, the concentration may exceed the MSL. This may occur when substantial amounts of soil $(>1 \mathrm{mg} / \mathrm{L})$ are transmitted to FTM (Figure 1). This is most relevant under wet conditions (Christiansson et al., 1999), although in our study no effect of wet conditions was observed. Transmission of substantial amounts of spores from soil to FTM and contamination of FTM via surfaces of the milking equipment were not assessed in this study or in previous studies on contamination of FTM by B. cereus spores (Te Giffel et al., 1995; Slaghuis et al., 1997; Christiansson et al., 1999). This may be due to the limited number of samples collected under specific conditions or the limited number of farms that took part in the surveys. To establish the relevance of these routes, it is essential to perform targeted measurements on a large group of farms with observed elevated $B$. cereus spore concentrations in FTM.

\section{CONCLUSIONS}

The results of this study showed that during housing and grazing, B. cereus spores in FTM most likely originated from feeds and were transmitted to FTM via feces and the exterior of teats. In the survey, however, none of the FTM samples contained a B. cereus spore concentration above the MSL ( $3 \log _{10}$ spores/L), indicating that transmission of $B$. cereus spores via this route seemed under control in Dutch circumstances. Nevertheless, it is very important to prevent the contamination of teats with soil during grazing because $B$. cereus spore concentrations in soil are approximately 100-fold higher than concentrations in other environmental carriers (feeds, feces, and bedding material). This implies that the transmission of relatively small amounts of soil, 1 to $13 \mathrm{mg} / \mathrm{L}$, can lead to a concentration in FTM that exceeds the MSL.

\section{REFERENCES}

Benedict, R. C., T. Patridge, D. Wells, and R. L. Buchanan. 1993. Bacillus cereus: Aerobic growth kinetics. J. Food Prot. 53:211214.

Christiansson, A., J. Bertilsson, and B. Svensson. 1999. Bacillus cereus spores in raw milk: Factors affecting the contamination of milk during the grazing period. J. Dairy Sci. 82:305-314.

Dewes, H. F. 1996. The rate of soil ingestion by dairy cows and the effect on available copper, calcium, sodium and magnesium. N. Z. Vet. J. 44:199-200.

Griffiths, M. W., and J. D. Phillips. 1990. Incidence, source and some properties of psychrotrophic Bacillus found in raw and pasteurized milk. J. Soc. Dairy Technol. 43:62-66.

ISO (International Organization for Standardization). 1983. Refrigerated bulk milk tanks. Pages 1-30. Vol. 5708. ISO, Geneva Switzerland.

Lin, S., H. Schraft, J. A. Odumeru, and M. W. Griffiths. 1998. Identification of contamination sources of Bacillus cereus in pasteurized milk. Int. J. Food Microbiol. 43:159-171.

NEN-ISO (Netherlands Normalisation Institute-International Organization for Standardization). 1994. Milk and milk productsEnumeration of Bacillus cereus and its spores. Vol. 6875. NENISO, Delft, the Netherlands.

Overcast, W. W., and K. Atmaram. 1971. The role of Bacillus cereus in sweet curdling of fluid milk. J. Milk Food Technol. 37:233-236.

Phillips, J. D., and M. W. Griffiths. 1986. Factor contributing to the seasonal variation of Bacillus spp. in pasteurized milk products. J. Appl. Bacteriol. 61:275-285.

Saran, A. 1995. Disinfection in the dairy parlour. Rev. Sch. tech. off. int. Epiz. 14:207-224.

Scientific Panel on Biological Hazards. 2004. Opinion of the Scientific Panel on Biological Hazards on Bacillus cereus and other Bacillus spp. in foodstuffs. EFSA J. 175:1-49.

Slaghuis, B. A., M. C. Te Giffel, R. R. Beumer, and G. Andre. 1997. Effect of pasturing on the incidence of Bacillus cereus spores in raw milk. Int. Dairy J. 7:201-205.

Stadhouders, J., and K. Jørgensen. 1990. Prevention of the contamination of raw milk by a hygienic milk production. Bull. Int. Dairy Fed. 251:32-36.

Stone, J. M., and A. Rowlands. 1952. "Broken" or "bitty" cream in raw and pasteurized millk. J. Dairy Res. 19:51-62.

Sutherland, A. D., and R. Murdoch. 1994. Seasonal occurence of psychrotrophic Bacillus species in raw milk, and studies on the 
interactions with mesophilic Bacillus sp. Int. J. Food Microbiol. 21:279-292.

Svensson, B., A. Eneroth, J. Brendehaug, G. Molin, and A. Christiansson. 2000. Involvement of a pasteurizer in the contamination of milk by Bacillus cereus in a commercial dairy plant. J. Dairy Res. 67:455-460.

Te Giffel, M. C., R. R. Beumer, M. H. Bonestroo, and F. M. Rombouts. 1996. Incidence and characterization of Bacillus cereus in two dairy processing plants. Neth. Milk Dairy J. 50:479-492.

Te Giffel, M. C., R. R. Beumer, B. A. Slaghuis, and F. M. Rombouts. 1995. Occurrence and characterization of (psychrotrophic) Bacil- lus cereus on farms in the Netherlands. Neth. Milk Dairy J. 49:125-138.

Vissers, M. M. M., F. Driehuis, M. C. Te Giffel, P. De Jong, and J. M. G. Lankveld. 2007a. Minimizing the level of butyric acid bacteria spores in farm tank milk. J. Dairy Sci. 90:3278-3285.

Vissers, M. M. M., M. C. Te Giffel, F. Driehuis, P. De Jong, and J. M. G. Lankveld. 2007b. Predictive modeling of Bacillus cereus spores in farm tank milk during grazing and housing periods. J. Dairy Sci. 90:281-292.

Walstra, P., J. T. M. Wouters, and T. J. Geurts. 2005. Dairy Science and Technology. Taylor and Francis, New York, NY. 